\title{
Fibromatosis of small intestinal ligament: a case report
}

\author{
Chen Liu \\ Department of Abdominal Ultrasound, the Affiliated Hospital of Qingdao University, Qingdao, China \\ Correspondence to: Chen Liu, MD. Department of Abdominal Ultrasound, the Affiliated Hospital of Qingdao University, Qingdao, China. \\ Email: nanchanghou@163.com.
}

\begin{abstract}
We provide a unique case of report of fibromation of small intestinal ligament in a patient with sigmoid colon cancer. This is the first case that one patient suffered these two kinds of tumor, as far as we know, there is no such case before. Due to his medical history of malignant cancer, so the fibromation of small intestinal ligament was suspected to be a metastatic lesion when it was found by radiologists, so operation had been performed. Finally, it was confirmed by pathological result. After the operation and postoperative chemotherapy, the two masses were removed and the patient had no significant complications, during follow-up, the patient is gradually recovering. In general, the disease should be taking into consideration when patient suffered malignant cancer, although it is very rare. In addition, ultrasound guided biopsy is a feasible method to diagnose the disease.
\end{abstract}

Keywords: Fibromation of small intestinal ligament; sigmoid colon cancer; ultrasound; case report

Submitted Dec 06, 2019. Accepted for publication Apr 09, 2020.

doi: 10.21037/apm-19-586

View this article at: http://dx.doi.org/10.21037/apm-19-586

\section{Introduction}

The fibroma of the ligament is a kind of rare borderline tumor, which is more common located at fascial or tendon membrane, and is characterized by local infiltration, destructive growth and easy recurrence (1). The local invasion and destructive growth cause the reconstruction of the tissue and the destruction of important structures and organs $(1,2)$. The incidence of the disease is $0.03 \%$ of all the tumors, accounting for less than $3 \%$ of all soft tissue tumors, and the incidence of the disease is only 2-4/1 million (1). One patient was admitted to our hospital with ileal end ligament fibroma, and the disease was found by accident due to sigmoid colon cancer treatment. It is reported as follows. We present the following case in accordance with the CARE Reporting Checklist.

\section{Case presentation}

A 51-year-old male who admitted to hospital due to the irregular stool (3 to 4 times of daily stool, not formed, even with blood) for 2 months. Clinically his vital signs were blood pressure (BP) 132/97 millimeters of mercury
( $\mathrm{mmHg}$ ), pulse rate of 121 beats per minute (bpm), respiratory rate 18 breaths per minute (BPM), pulse oximetry of $96 \%$ on room air and temperature at 36.6 degrees Celsius (C). In addition, the medical history of the patient was insignificant. Ultrasound showed hypoechoic masses in the right lower abdomen, the size of which was about $5.2 \mathrm{~cm} \times 3.7 \mathrm{~cm}$ (Figure 1A). Color Doppler flow imaging (CDFI) showed no obvious blood flow signal. Computed tomography (CT) showed that irregular mass located at the right pelvic cavity about $4.0 \mathrm{~cm} \times 3.8 \mathrm{~cm}$, with non-enhanced density (Figure $1 B$ ). Radiologists considered this to be a metastasis of sigmoid colon cancer. Surgical findings: a mass was found on the small intestinal wall, mainly located in the ileal wall, which seemed to involve the intestinal mucous membrane. Fusiform intercellular tumor was confirmed by pathology Figure 2, and immunohistochemical result as follows: CD117(-), CD34(-), DOG1(-)SMA(-)Desmin(-), Vimentin(++), S-100(-), calponin(+), B-catenin(++), ALK(-), Ki-67(+<2\%). The lesion of sigmoid colon cancer which was defined as T2N2M0 was resected with no notable incidences during the operation, and treated with postoperative chemotherapy (The FOLFOX6: 2-week cycles of intravenous $100 \mathrm{mg} / \mathrm{m}^{2}$ 

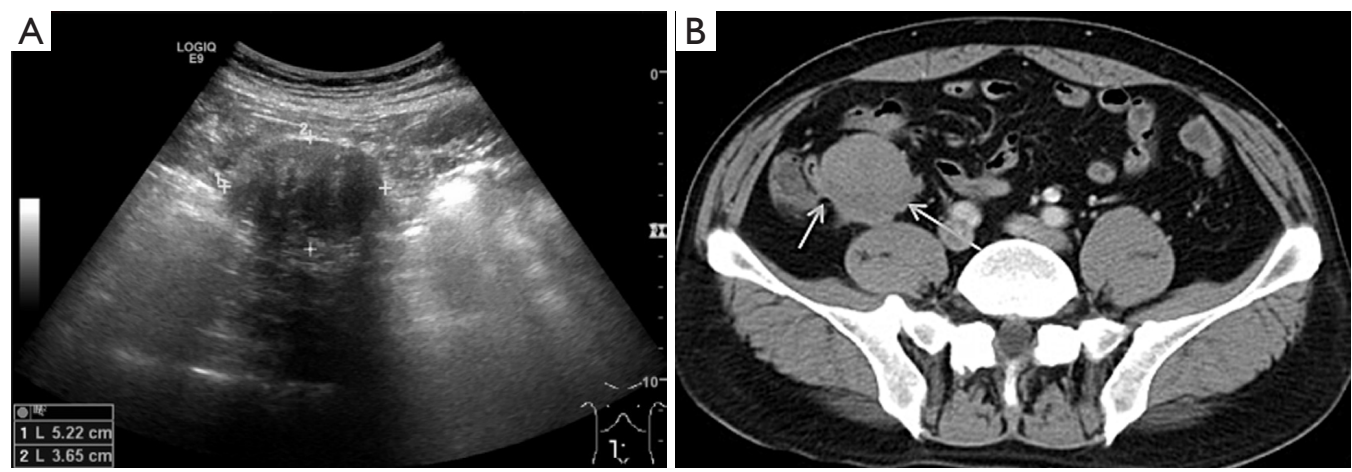

Figure 1 Imaging findings. (A) Ultrasound showed that the boundary of the mass was clear, some of the boundary seemed to adhere to the surrounding tissue, the internal echo was uneven, and the posterior part was accompanied by sound shadow. (B) Enhanced CT arterial phase shows a uniformly dense tumor (referred to by a long arrow), with part of the boundary connected to the small intestine (as indicated by the short arrow).
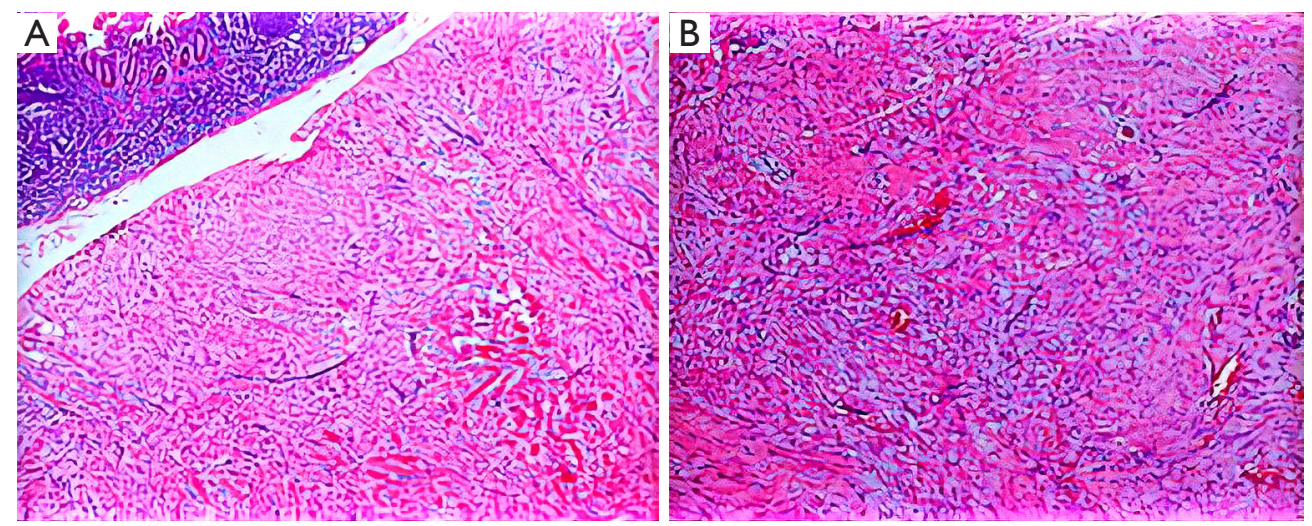

Figure 2 Pathological diagnosis. (A) Inherent myometrium and submucosal infiltration of small intestine, non-penetrating mucosa (H\&E, $\times 40)$; (B) The spindle and stellate cells arranged in the bundle were deposited in dense collagen stroma $(\mathrm{H} \& \mathrm{E}, \times 200)$.

oxaliplatin and $400 \mathrm{mg} / \mathrm{m}^{2} \mathrm{FA}$ over $2 \mathrm{~h}$ on day 1 of each cycle, plus $400 \mathrm{mg} / \mathrm{m}^{2}$ bolus $5-\mathrm{FU}$ with $2,400 \mathrm{mg} / \mathrm{m}^{2}$ infusional $5-\mathrm{FU}$ in $46 \mathrm{~h}$ for each cycle. The median duration of chemotherapy was six cycles). The patient was satisfied with the treatment plan developed by the hospital and was very cooperative with the treatment.

The condition of the patient's body was poor after the operation, so the radiotherapy was not performed. The patient was still alive until the last follow-up (Nov 1, 2019), his serum tumor markers showed normal results: CA199 (2.6 units $/ \mathrm{mL}$ ), radiological result showed no recurrence and no significant complication was documented. The timeline of this patient's historical and current information was made as Figure 3.

Written informed consent was obtained from the patient for publication of this case report and any accompanying images.

\section{Discussion}

The patient in this case was characterized by a fibroma of the small intestine at the same time suffered with sigmoid carcinoma. The location of ligament fibromatosis is also a place where sigmoid colon cancer is prone to metastasis, which makes it difficult to diagnose, and of course, it is rare. Although the main diagnosis of the patient is sigmoid colon cancer, However, the ligament fibroma of right lower abdomen is the most worthy of our discussion. In this case, we took full advantage of CT and ultrasound examination to show the accurate shape and location of the lesion, so 


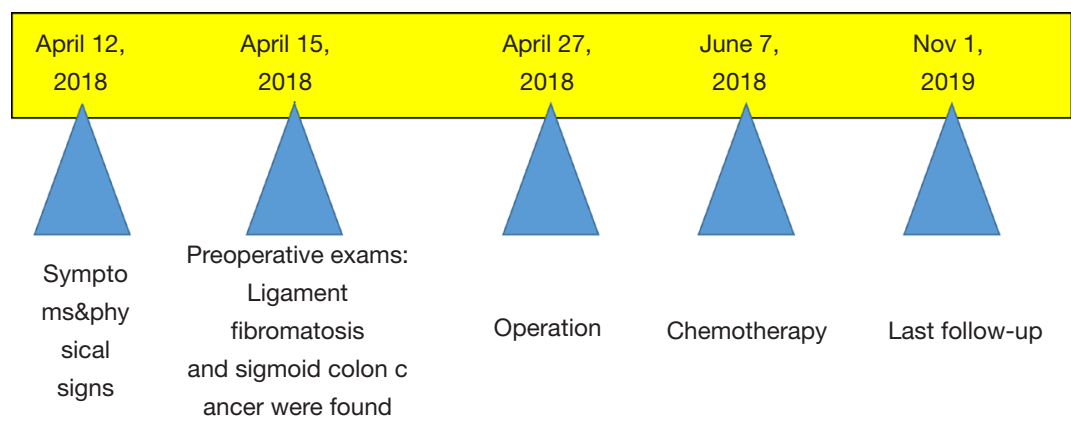

Figure 3 The timeline of the patient's historical and current information of care.

as to analyze the lesion as accurately as possible. There is no doubt that this was very important for the retrospective study of the disease. Limitation in this case was that we did not use other ultrasound techniques (such as ultrasound elastic imaging or contrast-enhanced ultrasound) to do further research for this case in order to distinguish the ligament fibroma from metastatic lesion. And ultrasoundguided biopsy was also not performed.

Ligament fibromatosis, also known as invasive fibromatosis, can be divided into abdominal wall type, extraabdominal type and intraabdominal type according to the site of occurrence. The abdominal type (this case) mainly originated from the mesentery, generally lacking typical symptoms, only when the tumor volume increased and squeezed the surrounding organs, the clinical symptoms (abdominal mass, abdominal pain or gastrointestinal bleeding, etc.) can present (3). Because of the lack of specific imaging performance, the diagnosis of ligament fibroma needs to be combined with the histological examination. In this case, the lesion of the patient was located at the end of the ileum, the location was deeper, the ultrasound was affected by the intestinal gas, and the ultrasound figure lacked of specificity, so it was easy to be confused with other tumors of the abdominal cavity, such as the stromal tumor, the lymphoma, and the ovarian source. In this case, the CT of the patient showed this lesion showed slightly lower density, the enhancement of the moderate enhancement of the arterial phase, the moderate strengthening of the venous phase and the delay period. It is required to be distinguished with the neurogenic or myogenic tumor $(4,5)$.

The fibroma of the ligament can only be confirmed histologically. Under the light-microscope, the fibroblastic and a small amount of myofibroblastic cells are aggregated into a mass, and there is a lack of significant cell heterotype, a little nuclear fission image can be seen, and the interstitial collagen of the tumor is obvious. Focal lymphocyte infiltration and myxoidosis are common (6). The ligament fibroma is a tumor of the poor blood supply, and is typically characterized by the invasive growth of the tumor cells or the adhesion to the surrounding tissue. In addition, the diagnosis of ligament fibromatosis by immunohistochemistry is mainly based on the following criteria: Vimentin and $\beta$-catenin are strongly positive; SMA, Desmin and CD117 can be positive; but CK, CD34 and S-100 are not expressed $(6,7)$. The immunohistochemical result of the patient in this case met the above characteristics.

Surgical resection is still the main way to treat the disease. For patients who are difficult to cure, good therapeutic effect can be obtained by radiotherapy or adjuvant chemotherapy such as vincristine and cyclophosphamide (8).

Although most of the literature on ligament fibromatosis appears in the form of case report, this disease has attracted more and more clinicians' attention, which has also contributed to the progress of clinical medicine. We report a case of intestinal ligament fibromatosis accompanied by sigmoid colon cancer. It is hoped to deepen the understanding of the disease. Although the incidence of the disease is low, the combination of imaging and immunohistochemistry is helpful to make a correct diagnosis.

\section{Acknowledgments}

Funding: None.

\section{Footnote}

Conflicts of Interest: The author has no conflicts of interest to 
declare.

Ethical Statement: The author is accountable for all aspects of the work in ensuring that questions related to the accuracy or integrity of any part of the work are appropriately investigated and resolved. All procedures performed in studies involving human participants were in accordance with the Declaration of Helsinki (as revised in 2013). Written informed consent was obtained from the patient for publication of this case report and any accompanying images.

Open Access Statement: This is an Open Access article distributed in accordance with the Creative Commons Attribution-NonCommercial-NoDerivs 4.0 International License (CC BY-NC-ND 4.0), which permits the noncommercial replication and distribution of the article with the strict proviso that no changes or edits are made and the original work is properly cited (including links to both the formal publication through the relevant DOI and the license). See: https://creativecommons.org/licenses/by-nc-nd/4.0/.

\section{References}

1. Sandberg AA, Bridge JA. Updates on the cytogenetics and molecular genetics of bone and soft tissue tumors:

Cite this article as: Liu C. Fibromatosis of small intestinal ligament: a case report. Ann Palliat Med 2020;9(4):2353-2356. doi: $10.21037 / \mathrm{apm}-19-586$ congenital (infantile) fibrosarcoma and mesoblastic nephroma. Cancer Genet Cytogenet 2002;132:1-13.

2. Shields CJ, Winter DC, Kirwan WO, et al. Desmoid tumours. Eur J Surg Oncol 2001;27:701-6.

3. Rampone B, Pedrazzani C, Marrelli D, et al. Updates on abdominal desmoid tumors. World J Gastroenterol 2007;13:5985-8.

4. Einstein DM, Tagliabue JR, Desai RK. Abdominal desmoids: CT findings in 25 patients. AJR Am J Roentgenol 1991;157:275-9.

5. Doi K, Iida $M$, Kohrogi N, et al. Large intra-abdominal desmoid tumors in a patient with familial adenomatosis coli: their rapid growth detected by computerized tomography. Am J Gastroenterol 1993;88:595-8.

6. Carlson JW, Fletcher CD. Immunohistochemistry for beta-catenin in the differential diagnosis of spindle cell lesions: analysis of a series and review of the literature. Histopathology 2007;51:509-14.

7. Chang CW, Wang TE, Chang WH, et al. Unusual presentation of desmoid tumor in the small intestine: a case report. Med Oncol 2011;28:159-62.

8. Kogelnik HD. Surgery versus radiotherapy for patients with aggressive fibromatosis or desmoid tumors. a comparative review of 22 articles. Strahlenther Onkol 2000;176:541-2. 